\title{
Technology and Computers in Music and Music Education
}

\author{
Nicholas Reynolds \\ Melbourne Graduate School of Education, The University of Melbourne, Australia \\ nreyn@unimelb.edu.au
}

\begin{abstract}
The use of computers in music education is investigated from a historical perspective that draws parallels to the use of computers in education generally. Drawing upon a study into the musical compositions of primary school children working in electronic environments this paper presents approaches to the use of ICT in music education that appear at odds with approaches in other education areas. The paper provides reasons for this and offers ways in which ICT can be used differently in music education research.
\end{abstract}

Keywords: Music, children's compositions, ICT, literature.

\section{Introduction}

In investigating the literature into ICT in music education as part of a twelve month study into the compositional process of children aged ten to twelve years in an electronic environment, the author became aware of a representation of the use of ICT as one very much situated in an instructional approach to music teaching, rather than in the more constructivist approaches that populate the ICT in Education literature at large. This paper presents some of the literature from music education and places it against literature about the use of ICT in a broader educational context. The contrast is made within the context of the research project.

\section{Background}

In an investigation of the compositions and compositional processes of children working in an electronic environment the current study required the children to engage in a number of loosely structured compositional tasks over much of a school year. Meeting weekly, the children were encouraged to compose music of their own choosing. Very little was given as instruction and rarely were considerations of form or convention mandated or even discussed. This allowed the researcher to examine what the children did musically rather than what they were taught about music through the use of ICT. The seven children in the study (four boys and three girls) frequently collaborated in their compositional tasks and in the production of some 250 compositions that demonstrated approaches to music, to music perception, to musical representation, to musical preference and to musical understanding that were made accessible through the interaction with ICT. 


\section{ICT in Music Education}

There still appears to be a focus in music education literature about what the technology is but little on what the technology means in terms of rich or different experiences for children. Work by Reynolds [1, 2] presents an approach that looks at the computer as something that allows the child to do something that could not be done without it. That approach draws heavily on the work of Papert [3] and McDougall [4]. Published work from the current study [5-8] presents views about how the computer allows us to investigate children's compositions and, perhaps more importantly, how it allows us to investigate and develop our own understandings about children's musical perceptions and understanding. A significant contributor to the development of our understanding is the fact that the computer allows us into the processes of composition in ways that have never before been possible. This approach is not specifically developmental, yet provides opportunities to look at musical development in different ways.

Computers and technology are viewed by Webster and Hickey [9] mainly from a perspective of computer-aided instruction (CAI). Their review of literature is one that is drawn mostly from sources that describe the uses of computers in the teaching of music. Their understanding of CAI fits with Papert's [3] less than flattering description made in the early 1980s where CAI "means making the computer teach the child" [3]. Papert's ideal is that the role of the computer is to be a "carrier of cultural 'germs' or 'seeds' whose intellectual products will not need technological support once they take root in an actively growing mind"[3] .

Webster and Hickey categorize software titles into music content by age group. Interestingly, they place Audacity, an open source, multitrack editing and recording application (and one of the programs used by the children in the aforementioned study) into their 'perception' category for 10-15 year olds, where it can be used to develop musical perception by playing teacher recorded examples of typical musical elements. In the current study the children used it not to listen to musical examples but as a compositional tool. In their 'creating' category for that age group they only list looping type titles such as GarageBand (a multitrack midi and audio program for Mac computers that operates through a process of dragging and dropping prerecorded clips onto a timeline) and Acid Studio (another multitrack midi and audio program that is typically used by dragging pre-recorded clips onto a timeline and 'looping' them). Looping software typically constrains the user into a rigid four beats to the bar framework and relies on the piling up of short melodic phrases that align themselves tonally and rhythmically to the timeline. Webster and Hickey place programs that are equivalent to Cakewalk, a multitrack midi sequencer and digital audio application (the other program used in the current study) into the 'creating' category for the 16-adult age group.

From a developmental music education perspective this categorization makes sense but it doesn't fit with ideas about the use of computers as the 'knowledge machines' that Papert proposed many years ago, or with the approaches to computers in children's music making adopted as part of the current study. The developmental approach adopted by Webster and Hickey also places them at odds with Papert's ideals. In the opening sections of his book, Mindstorms, Papert [3] describes the book's purpose (and his beliefs about computers in education) as follows: 
This book is about how computers can be carriers of powerful ideas and of the seeds of cultural change, how they can help people form new relationships with knowledge that cut across the traditional lines separating humanities from sciences and knowledge of the self from both of these. It is about using computers to challenge current beliefs about who can understand what and at what age. It is about using computers to question standard assumptions in developmental psychology and in the psychology of aptitudes and attitudes [3].

These ideas resonate very strongly with the approach taken in the current study and are presented here to demonstrate the significantly different approaches to and understanding of the use of computers by educators in all areas of education.

Webster and Hickey see the instant music making capacities of programs like $G a$ rageBand, Acid Studio and Sooper Dooper Music Looper (a junior and more constrained version of Acid that is designed specifically for primary aged children) as being potentially beneficial in developing musical perception, but argue that their use "needs to be tempered with expert teaching [that can] help challenge students to develop more sensitive and complex ways to think musically" [9]. They also call for more research into how these technologies "can be done well or in a way consistent with current theories" [9].

The notion that children don't already think in musically complex or sensitive ways is one that needs challenging, although not necessarily here but these complex and sensitive musical ways of thinking don't necessarily fit with developmental approaches, with accepted musical thinking or with educational outcomes. More importantly, the call to link technology use to existing theories demonstrates a certain cautious and traditional approach to research and to technology. While not discarding the existing theories, and acknowledging their importance, it is important to consider how new technologies allow for new investigations and understandings as well as the development of new theories. Accordingly, it is important to embrace the potential of computers to do much more than reinforcing musical instruction.

In a later chapter on computers and technology Webster [10] focuses on presenting a recent historical perspective, supported by older research. Unfortunately from the perspective of expanding the capacity of computers in music education, it offers no new ideas about the use of computers in understanding children's engagements with music or their own musical understandings. Despite the title including 'learning' the chapter is really a focus on 'teaching' with technology. This reinforces that cautious and traditional approach to the use of computers in music education.

Webster's investigation of computer technology to support composition is, as is much of the literature, either based on young adult musicians composing or children being given 'special' software that composes for them. Nothing could be further from the constructivist approaches of Papert and others.

As indicated by the Webster and Hickey, and the Webster chapters much of the literature around the use of computers in music education is about the computer as teacher. The examples of the ways children's music making is represented in the literature, provided later in this paper, demonstrate the pervasiveness of that approach.

Folkestad, Hargreaves and Lindström, [11], Nilsson [12], and Nilsson and Folkestad [13] have provided valuable studies on the use of technology in children's and young people's compositional approaches. Their studies focused on the role of the computer and peripheral hardware and software in the compositional processes of 
young people. The Folkestad studies investigated adolescent children, and the Nilsson studies younger children. The role of the computer in these studies was not that of teacher or instructor but one of participant in the creative and compositional processes of young people.

\section{ICT and Education}

A significant area of focus for the current study is the role of the computer and the electronic environment and the relationship the participants have with that environment in the compositions and compositional process. It is clear that musically the computer allows children to do things in new ways and to overcome musical technical deficiencies in order to compose or to create works of greater complexity (not the best choice of word in the context of this study) than they could without the computer $[1,12,14]$. Amongst other things children do not need to rely on other children to understand their ideas, they do not need to be able to notate a piece in order for it to be played, they do not need instrumental mastery in order to play their own works and they are presented with an almost unlimited canvas of instruments and sounds from which to create their pieces. The affordances of this environment are something that is particularly attractive to me. The following section presents an investigation of literature that is focused on research that investigates the enabling power of ICT in education.

Underpinning this study is a personal belief about the relationship that exists between children (young people) and computers. In using the term 'computers' much more is referred to than the box that sits on the desk; regardless of whether that box is a phone, a music player, a laptop (or netbook), a hand held device of any description or a standard personal computer like the ones used in this study. Papert's ideas of computers being knowledge machines are referred to earlier in this paper. These are powerful ideas (deliberate use of this term) and inform one significant part of this author's beliefs about computer use and children. Another significant part has its roots in the writings of John Perry Barlow. In the early 1990s Barlow experienced first hand a new form of interaction and communication in cyberspace and developed ideas about the nature of that 'place' and its 'inhabitants'. The idea that cyberspace affords completely different things to different groups of people is very appealing. More appealing is his description of a father's perspective of computers and cyberspace, which he refers to "as an immigrant's fear of a strange new land into which he will be forcibly moved and in which his own child is a native" [15]. This idea is expanded by Bigum and Lankshear [16], Lankshear and Bigum [17], and by Lankshear and Knobel [18] with a focus on the mindsets of the individuals using computers and interacting with cyberspace, and what that means for schools, schooling and learning. The notion of immigrants and natives is clarified by Lankshear and Bigum, who prefer the terms 'insiders' and 'newcomers'; they use Barlow to "distinguish the two broad mind sets identified; one affirms the world as the same as before, only more technologised; the other affirms the world as radically different, precisely because of the operation of new technologies" [17].

There are a number of parallels between the field of ICT in education research and the field of ICT in music education research. The first is that there has been a stream of focus that deals with tools and usage; what equipment is being used, how many 
schools/children are using it and attempted connections between technology and learning outcomes. Within this stream are many large projects and government reports into areas such as teacher attainment [19], pupil learning and attainment [20], student ICT literacy [21] school use [22] and, amongst other things, the impact of ICT on students [23].

A second stream, and one that has much more relevance to the current study, is that of educators working with technology as an enabler of different things. Building on the work of Papert, Resnick [24, 25] presents children's playful learning in creative and collaborative environments while working with the programming application, Scratch. In these environments children are encouraged to explore new and different ways of communicating ideas and of collaborating with each other on a global or local level. This focus on children making, creating, exploring, playing and communicating, and what happens when they do those things in electronic environments is closely aligned to the kinds of computing that are represented in the current study.

Narayanan [26], also working with Scratch and with Pico Crickets (programmable interactive devices) presents a view of technology enabled learning that fits with a philosophy of Slow Schooling, where time is taken, not in getting through the curriculum but in experiencing the physical and virtual environment. Her work with impoverished slum dwellers in Bangalore presents a use of technology that connects the child with their environment and allows them to interact with it and investigate it while at the same time developing language, computer and cultural skills. The technology is central to her work but it is never taught. Narayanan asks a series of questions that relates to her beliefs about "the landscapes of education and technology"

- Have the contours of this landscape been created by the tools of technology defining the nature and scope of the learning environment?

- Or have the contours of this new landscape been defined by learning needs and contexts which in turn inform the creation and sustaining of digital or virtual learning worlds?

- Are the horizons of this landscape defined by the convergence of traditional literacies integrated with conventional and new medias?

- Or do the distributed networks of new media define both the horizon and reach of the communication and literacy agendas of teachers and educators?

- Should the development goals of education with technology focus on the development of the brain, the intellect and the mind?

- $\quad$ Or is about developing the heart and expanding the inner self? [26]

The well known work of Sugata Mitra and his Hole in the Wall projects is another example of the use of technology in education as an enabler of powerful things. Mitra, like Narayanan does not engage in any instruction of technology, preferring to observe children playing, experimenting and teaching themselves about the electronic environments that they are beginning to experience. In a significant body of work Mitra and colleagues [27-31] present a Minimally Invasive Education (MIE) model in which the principles of play and experimentation underpin a learning environment that is non instructional and which encourages peer support. This model is applied across the curriculum and places the learning and the technology in the hands of the learner. 
Throughout this body of work, running alongside the notion of MIE, is the idea of learning as "a self organizing system". Mitra puts it this way:

Self organizing systems have low predictability, they are 'grown' and not 'made'. In a sense, they represent our transition from the industrial to the information age. 'Making it happen' was the management paradigm of the age gone by. 'Letting it happen' will be the strategy for building the systems of the new age. The real paradigm shift in education will be the conversion of the educational process into selforganizing systems. [29]

These ideas represent an approach to education and to ICT in education that has its genesis in the works of Papert and is an example of the "modern traditionalism" that McDougall [32] proposes educators who use ICT engage in; an acknowledgement of the important work done by thinkers like Papert in the Twentieth Century. It, like that of Resnick and Narayanan, and the current study, also has its roots firmly planted in the acknowledgement of the centrality of play.

Narayanan's responses are also driven by a desire to connect with and to a lost culture. The Burarra talking book project [33] is an example of the use of technologies in the recording and presentation of indigenous languages to Indigenous Australian children in order to develop literacy in what is their first language.

The Burarra project, like that of Narayanan's is an example of educational technology outside the realms of 'traditional' schooling and is an example of the learning being placed in the hands of the learner, supported by technology with minimal (visible) intervention. It takes technology out of what Narayanan calls the "plenitude'. For her this plenitude is an example of and a result of old ways of thinking that do not see what technology can do and be. She says:

What I also realize is that our contemporary notion of school is a place where the official curriculum is driven by ideas and attitudes that are expressed or implied in the materials, textbooks and technology that form yet another plenitude that is engulfing teachers, curriculum designers and policy makers. This is due to in large part to conventional thinking about digital technologies and learning, a way of thinking that argues that more technology, greater access and better connectivity will deliver faster learning for more learners across far distances in short periods of time [26].

There is strong resonance here with the ideas of Barlow and Lankshear discussed earlier where the mind set of the educator needs to acknowledge the mind sets of the learner when using digital technologies and the perceived affordances therein.

The work of Vincent [34, 35] in investigating the relationships between learning styles, multimedia and the crossing of semiotic boundaries is another example of the this second stream of ICT in education research that asks what happens when children can play and explore with computers, what things can they do with computers that they couldn't do without them and most importantly, what can we learn about the ways children think and learn.

The examples presented from what is termed above as the second stream are only a sample from the literature that demonstrate a way of thinking about and investigating the ways in which computers and computer technologies are used in educational settings with children. An investigation that looks at the relationship with the environment can easily accept the ideas of Barlow and his notion of mindsets and cyberspace. His 
ideas are in accord with those of Papert who said that when computers "enter the private worlds of children everywhere. They will do so not as mere physical objects" [3].

\section{Children's Use of ICT as Represented in the Music Literature}

There are an increasing number of studies that look at the use of ICT in the compositional approaches of children. The following section presents, very briefly, some of those examples and attempts to show typical use of ICT in music education research. It will be contrasted with examples from the current study to highlight the significant differences in approaches. The most significant difference is in the acknowledgement that children don't necessarily understand or work within strict conventional time structures. A problem for researchers is the graphical representation of children's compositions. In order to represent those compositions in a manner that can be understood by the reader it is necessary to convert an audio recording or a child's play into a notation system that was not applied by the child at the time of composition. In the following examples researchers have either chosen to represent children's compositions in ways that are understandable to the reader or they have manipulated the software (before the child started composing) in order to adhere to western musical convention.

Nilsson [12] presents examples of children's compositions using Cubase Score, a midi sequencer and notation program all examples are presented in strict four/four timing with perfectly placed notation; an indication that either the files were 'quantized' (a process in midi sequencers wherein note lengths and starting positions are moved in order to create regular beat and rhythm) or the notation representation was made at a quaver or semi quaver resolution (midi notation programs allow for notes to appear to have been 'quantized' without actually changing the played values).

Jennings [36] presented one ten year old child's work that was composed with the specially designed children's compositional software, Hyperscore. He represents the child's work as screenshots from the software. These screenshots show 'blobs' of sound that are placed along a ruler, these 'blobs' can be arranged vertically and horizontally. Interestingly, Jennings's subsequent examples are those of compositions made after teacher intervention "designed to encourage Kevin (student's name) to move beyond the superficial exploration of the interface and reframe the task in a musical context" [36]. These examples show perfectly lined up regular four bar

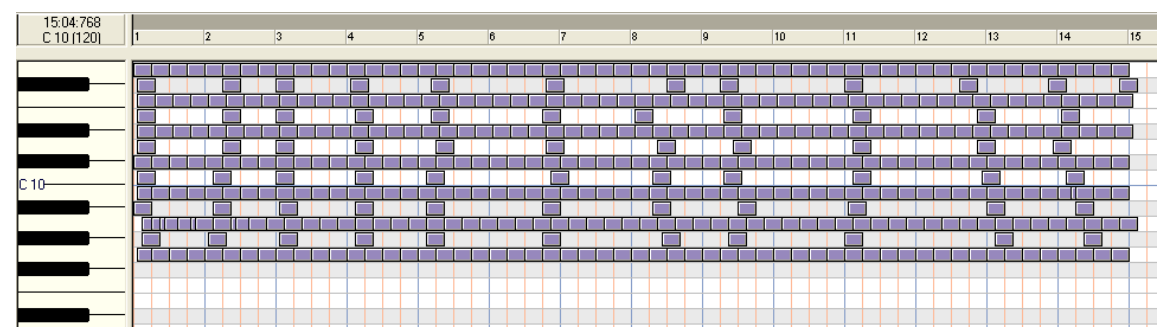

Fig. 1. Track 3 from Student Na's Piano Roll piece 


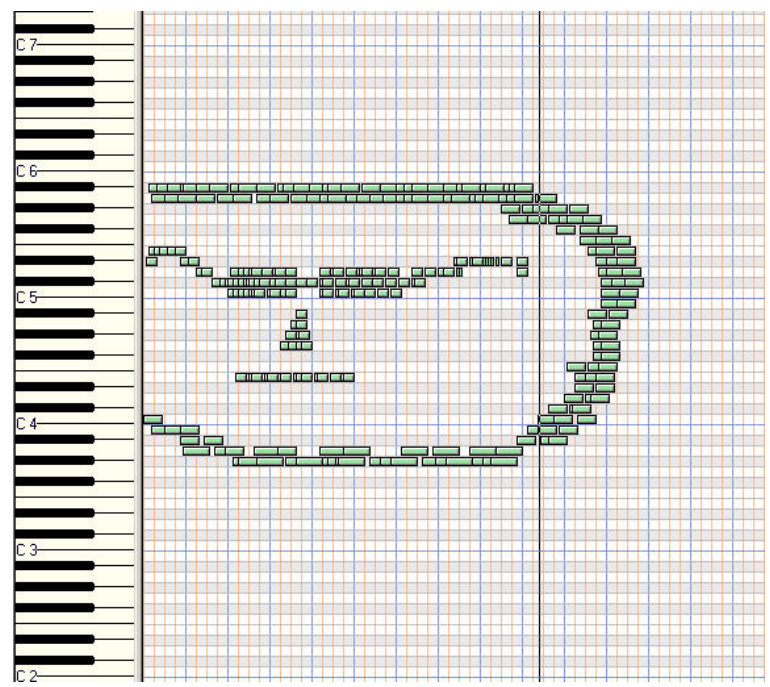

Fig. 2. Student L's Face composition

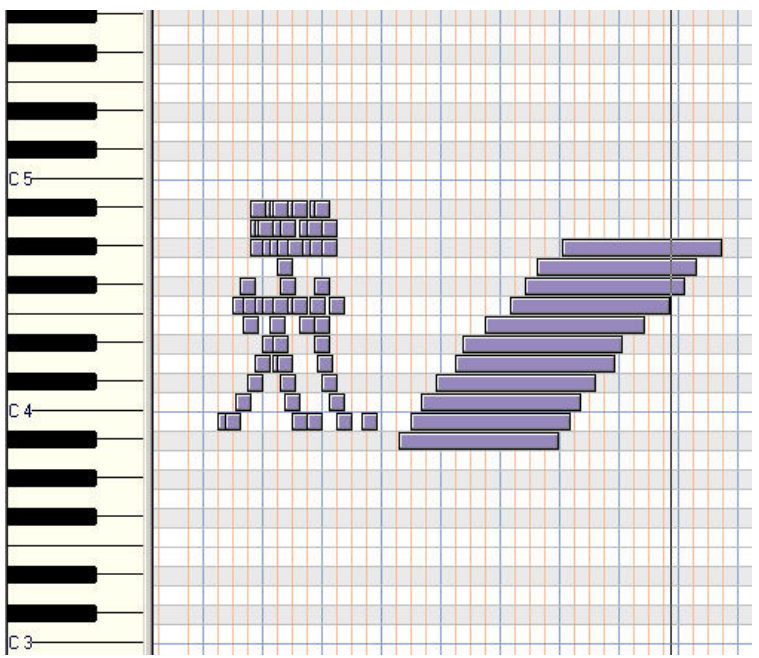

Fig. 3. Student N's The Golfer composition

patterns. The inference from Jennings is that the initial compositional example was somehow 'wrong' and that teacher intervention was required to 'fix it'.

Wilson and Wales [37] provide examples of children's compositions in their investigation of the complexity of children's compositions through the focus on melodic and rhythmic stages of development. Their study used the musical notation software, Music Works. In this application notes are placed onto a stave using the mouse. Note values are presented in a palette and notes must be selected from the palette and dropped onto the stave to represent pitch and rhythm. 
It is difficult to select three examples from more than 250 but these three are representative of one approach to composition that the children engaged in. Through the use of the piano roll view in Cakewalk the children played with the notion of 'drawing' their compositions. Examples from the current study show a complete lack of understanding or consideration for conventional beat and time structures. The following examples are screenshots of children's compositions. The first example, figure 1, is not a drawing but is a visually constructed piece where layers of sound are built up and intersected. The composer's idea here was to play with those layers. The only rhythmic regularity is in the note length.

The next two examples are of musical 'pictures'. The first, figure 2, is of a face. This work, by Student L, was composed as a picture. The musical consideration (sound) was of secondary importance. The piece was, however, listened to critically by the composer.

The final example, figure 3, is an example of the layering of sound combined with a drawing. The golfer in the picture appears to be attempting to play up the 'hill' of layered notes. The composer was, however, just playing with look and sound.

\section{Conclusion}

The author is of the opinion that researchers of children's musical compositions work around notions of melodic and harmonic structure. Typically children's works are presented in a way that demonstrates skill, or lack of it, in melodic development, sequencing, awareness of harmony and rhythmic structure. Assumptions are either made about children's understandings of these features or the way the data was collected or analyzed did not allow for these features to be fully investigated without adult intervention. This might sound like a criticism of previous research; for the most part it is most certainly not. The work of Swanwick, Swanwick and Tillman, Folkestad, Nilsson, and Barrett, to name a few, are of significant importance; their focus and analyses are different from those of the current study, and so the way they discuss children's compositions is different. They are highlighted here in order to draw attention to the difference and because of their importance within the literature. The difference is also highlighted to demonstrate that through the use of ICT it is possible to venture into new and exciting possibilities and understanding about the way children learn and understand.

\section{References}

1. Reynolds, N.J.: Primary School Creativity and Composition in a Professional Level Music Software Environment. Faculty of Education, M ITEd. University of Melbourne, Melbourne, 110 (2001) (plus appendices)

2. Reynolds, N.J.: Computers, Creativity and Composition in the Primary School: An analysis of two compositions. Australian Journal of Music Education 1, 16-26 (2002)

3. Papert, S.: Mindstorms: Children, computers, and powerful ideas. Harvester, Brighton (1980) 
4. McDougall, A.: Children, recursion and Logo programming: An investigation of Papert's conjecture about the variability of Piagetian stages in computer-rich cultures. In: McDougall, A., Dowling, C. (eds.) Computers in Education, IFIP TC 3 5th World Conference on Computers in Education - WCCE 1990. Elsevier Science, Sydney (1990)

5. Reynolds, N.J.: The Computer as Scaffold, Tool and Data Collector: Children Composing with Computers. Education and Information Technologies 10, 239-248 (2005)

6. Reynolds, N.J.: Seeking Affordances: searching for new definitions and new understandings of children's relationships with technologies in musical compositions. Australian Educational Computing 23 (2008)

7. Reynolds, N.J.: An Ecological Approach to ICT and Children. In: Benzie, D., Zammit, K. (eds.) IFIP WG 3.5 International Conference - Valuing individual and shared learning: the role of ICT. Charles University in Prague, Czech Republic (2008)

8. Reynolds, N.J.: When wrong is right: Understanding children's electronic compositions. In: ASME XVII National Conference: Musical Understanding. ASME, Launceston (2009)

9. Webster, P., Hickey, M.: Computers and Technology. In: McPherson, G. (ed.) The Child as Musician, pp. 375-395. Oxford University Press, Oxford (2006)

10. Webster, P.: Computer-Based Technology and Music Teaching and Learning: 2000-2005. In: Bresler, L. (ed.) International Handbook of Research in Arts Education; Part Two, pp. 1311-1328. Springer, Dordrecht (2007)

11. Folkestad, G., Hargreaves, D.J., Lindström, B.: Compositional Strategies in ComputerBased Music-Making. British Journal of Music Education 15, 83-97 (1998)

12. Nilsson, B.: "I can always make another one!" - Young musicians creating music with digital tools. In: Leong, S. (ed.) Musicianship in the 21st Century: Issues, Trends and Possibilities, pp. 204-218. Australian Music Centre, Sydney (2003)

13. Nilsson, B., Folkestad, G.: Children's practice of computer-based composition. Music Education Research 7, 21-37 (2005)

14. Barrett, M.: Meme Engineers: children as producers of musical culture. International Journal of Early Years Education 11, 195-212 (2003)

15. Barlow, J.P.: Crime and Puzzlement 1, vol. 2005 (1990)

16. Bigum, C., Lankshear, C.: Literacies and technologies in school settings: Findings from the field. In: Keynote address to 1998 ALEA/ATEA National Conference, Canberra, vol. 2005 (July 1998)

17. Lankshear, C., Bigum, C.: Literacies and new technologies in school settings. Pedagogy, Culture \& Society 7, 445-465 (1999)

18. Lankshear, C., Knobel, M.: Mapping postmodern literacies: A preliminary chart. The Journal of Literacy and Technolgy 1 (2000)

19. Cox, M.J., Abbott, C. (eds.): ICT and Attainment: a review of the research literature. BECTA / DfES, London (2004)

20. Harrison, C., Comber, C., Fisher, T., Haw, K., Lewin, C., Lunzer, E., McFarlane, A., Mavers, D., Scrimshaw, P., Somekh, B., Watling, R.: ImpaCT2: The Impact of Information and Communication Technologies on Pupil Learning and Attainment. BECTA, London (2003)

21. Ainley, J., Fraillon, J., Freeman, C.: National Assessment Program: ICT Literacy Years 6 and 10 Report 2005. MCEETYA, Carlton South (2007)

22. Cuban, L., Kirkpatrick, H., Peck, C.: High Access and Low Use of Technologies in High School Classrooms: Explaining an Apparent Paradox. American Educational Research Journal 38, 813-834 (2001)

23. Condie, R., Munro, R.: The Impact of ICT in schools - a Landscape Review. BECTA, Coventry (2007) 
24. Resnick, M.: Rethinking learning in the digital age. In: Kirkman, G. (ed.) The Global Information Technology Report: Readiness for the Networked World. Oxford University Press, New York (2002)

25. Resnick, M.: Sowing seeds for a more creative society. Learning \& Leading with Technology 35, 18-22 (2008)

26. Narayanan, G.: Moving beyond the Plenitude: An Indian Fable. In: ED-MEDIA World Conference on Educational Multimedia, Hypermedia \& Telecommunications. AACE, Vienna (2008)

27. Mitra, S.: Self organising systems for mass computer literacy: Findings from the "hole in the wall' experiments. International Journal of Development Issues 4, 71-81 (2005)

28. Mitra, S., Rana, V.: Children and the Internet: Experiments with minimally invasive education in India. The British Journal of Educational Technology 32, 221-232 (2001)

29. Mitra, S.: Children and the Internet: New Paradigms for Development in the 21st Century. In: Asian Science and Technology Conference, Tokyo, Japan (2000)

30. Mitra, S., Dangwal, R., Chatterjee, S., Jha, S., Bisht, R., Kapur, P.: Acquisition of computing literacy on shared public computers: Children and the 'Hole in the Wall' Australasian. Journal of Educational Technology 21, 407-426 (2005)

31. Inamdar, P., Kulkarni, A.: 'Hole-In-The-Wall' Computer Kiosks Foster Mathematics Achievement - A comparative study. Educational Technology \& Society 10, 170-179 (2007)

32. McDougall, A.: Twenty years of Australian Educational Computing: A call for modern traditionalism. Australian Educational Computing 20, 11-13 (2005)

33. Auld, G., Darcy, R.: The production and distribution of Burarra Talking Books. Australian Educational Computing 23, 19-23 (2008)

34. Vincent, J.: Writing and Coding: Assisting writers to cross the modes. Language and Education 21, 141-157 (2007)

35. Vincent, J.: Computer mediated multimodal text production: ten-year-olds crossing semiotic boundaries. Lambert Academic Publishing, Cologne (2009)

36. Jennings, K.: Hyperscore: A case study in computer mediated musical composition. Education and Information Technologies 10, 225-238 (2005)

37. Wilson, S.J., Wales, R.J.: An exploration of children's musical compositions. Journal of Research in Music Education 43, 94-111 (1995) 